\title{
The concentrations of clarithromycin and its 14-hydroxy metabolite in sputum of patients with bronchiectasis following single dose oral administration
}

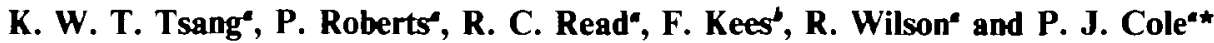 \\ ${ }^{a}$ Host Defence Unit, The Royal Brompton National Heart and Lung Institute, Manresa \\ Road, London SW3 6LR, UK; ${ }^{b}$ Department of Pharmacology, University of \\ Regensburg, 31-D-8400, Regensburg, Germany
}

\begin{abstract}
Clarithromycin and its metabolite, 14-hydroxy-clarithromycin are active against a wide range of respiratory pathogens. Antibiotics generally penetrate poorly into respiratory secretions which may therefore continue to harbour bacteria following bronchial infection. We have studied sputum and serum concentrations of clarithromycin and 14-hydroxy-clarithromycin in eight patients with idiopathic bronchiectasis without infective exacerbations (five male, three female; mean age 53.3 years). Oral single dose administration of 250 or $500 \mathrm{mg}$ clarithromycin, separated by at least 6 days, was given to each patient. Serum and sputum samples were collected (the latter by physiotherapy at $0,1,2,4,8,24$ and $0,4,8$ and 24 h respectively after administration of each dose. Serum sol phase was obtained by high speed centrifugation and concentrations of clarithromycin and 14-hydroxy-clarithromycin were determined by high performance liquid chromatography. Serum $C_{\max }$ for clarithromycin and 14-hydroxy-clarithromycin were $1.20 \mathrm{mg} / \mathrm{L}(3 \mathrm{~h})$ and $0.37 \mathrm{mg} / \mathrm{L}(3.1 \mathrm{~h})$ for clarithromycin $(250 \mathrm{mg}))$ and were $2.78 \mathrm{mg} / \mathrm{L}(2.5 \mathrm{~h})$ and $0.68 \mathrm{mg} / \mathrm{L}(2.6 \mathrm{~h})$ for clarithromycin $(500 \mathrm{mg})$ respectively. Sputum $C_{\max }$ for clarithromycin and 14 hydroxy-clarithromycin were $0.52 \mathrm{mg} / \mathrm{L}(5 \mathrm{~h})$ and $0.30 \mathrm{mg} / \mathrm{L}(6.5 \mathrm{~h})$ for clarithromycin $(250 \mathrm{mg})$ and were $1.59 \mathrm{mg} / \mathrm{L}(5 \mathrm{~h})$ and $0.47 \mathrm{mg} / \mathrm{L}(5.5 \mathrm{~h})$ for clarithromycin $(500 \mathrm{mg})$ respectively. The sputum/serum percentage ratios at $C_{\max }$ (sputum) for clarithromycin and 14-hydroxy-clarithromycin were $74.3 \%$ and $113.9 \%(250 \mathrm{mg})$ and $94.7 \%$ and $99.9 \%(500 \mathrm{mg})$ respectively. We conclude that oral administration of clarithromycin to patients with bronchiectasis results in rapid penetration into respiratory mucus with persistent drug concentrations that exceed its MIC for many respiratory pathogens.
\end{abstract}

\section{Introduction}

Clarithromycin is a new macrolide antibiotic which is a 6-methoxy derivative of erythromycin. Clarithromycin is more resistant to gastric acid and has a better pharmacokinetic profile than erythromycin. A metabolite of clarithromycin, 14 hydroxy-clarithromycin, also has antibiotic activity against Haemophilus influenzae. Clarithromycin and 14-hydroxy-clarithromycin have an additive effect which reduces the MIC for this bacterium (Hardy et al., 1990). Clarythromycin has been shown to be effective in patients with infective exacerbations of chronic obstructive lung disease (Guay \& Craft, 1992).

*Corresponding author. 
Recent studies (Farley et al., 1986; Baltimore, Christie \& Walker-Smith, 1989; Read et al., 1991) have suggested that bacteria infecting the bronchial tree are largely associated with intraluminal secretions, rather than adherent to epithelial surfaces. Therefore a high concentration of antibiotic in sputum is desirable. However the penetration of many antibiotic classes into secretions is poor (Bergogne-Berezin, 1988; Valcke, Pauwels \& Van der Straeten, 1990). Although the penetration of clarithromycin into lung tissue has been measured, its penetration into secretions has not. We have therefore performed an open study of serum and sputum concentrations of clarithromycin and 14-hydroxy-clarithromycin following single oral administration of 250 and $500 \mathrm{mg}$ of clarithromycin in patients with idiopathic bronchiectasis.

\section{Materials and methods}

\section{Patient recruitment and specimen collection}

Patients with bronchiectasis confirmed by high resolution thin-cut computerized tomography were enrolled at a time when their symptoms were stable, there having been no infective exacerbation within the last 30 days. Patients who regularly produced mucoid sputum were selected. Nine patients were enrolled during the study period. One patient was withdrawn from analysis because insufficient sputum was obtained. Analysis was performed on eight patients (five male and three female; mean age 53.3 years, S.D. 13.04, range 37-71) who had clinically stable idiopathic bronchiectasis. Mean height was $166.9 \mathrm{~cm}$ (S.D. 10.4, range 150-182.0) and mean weight was $64.5 \mathrm{~kg}$ (S.D. 17.9, range 38-93). All patients had normal liver function tests before entering the trial. No patient had used any concomitant antibiotic, theophylline, carbamazepine, warfarin, digoxin or long-acting (depot) antibiotics within 30 days before the study.

The first dose of clarithromycin $(250$ or $500 \mathrm{mg}$ ) was administered orally following an overnight fast, after physiotherapy to clear residual secretions. Serum and sputum specimens were collected at $0,1,2,4,8,24$ and $0,1,4,8$ and $24 \mathrm{~h}$ after administration respectively. At least six days were allowed before the patients returned for their second dose of clarithromycin ( 250 or $500 \mathrm{mg}$ ) when specimens were collected similarly. Fresh sputum specimens were collected by a physiotherapist who provided assistance with postural drainage. Immediately after collection, serum was obtained by centrifugation of blood at $1000 \mathrm{~g}$ for $5 \mathrm{~min}$ at $4^{\circ} \mathrm{C}$. Sputum and serum specimens were stored in sterile containers at $-70^{\circ} \mathrm{C}$. Patients provided written informed consent, and the study was approved by the Ethics Committee of the Royal Brompton National Heart and Lung Hospital.

\section{Analysis of specimens}

The concentrations of clarithromycin and 14-hydroxy-clarithromycin in serum and sputum (sol phase) specimens were analysed using high performance liquid chromatography. The apparatus consisted of a pump LKB 2248 with pulse dampener (Pharmacia, Freiburg, Germany); autosampler SIL-8A (Shimadzu Europe, Duisburg, Germany); column heater TCM $100\left(30^{\circ} \mathrm{C}\right.$, Millpore Waters Chromatography, Eschborn, Germany); electrochemical detector (Coulochem model 5100A: guard cell 5020 set to $1 \mathrm{~V}$, analytical cell 5010 with electrode 1 set to $0.65 \mathrm{~V}$ and electrode 2 (for quantitation) set to $0.85 \mathrm{~V}$ ) (ESA Inc., Bedford, MA, USA); and integrator C-R4A (Shimadzu Europe, Duisburg, Germany). Separation was conducted using a Zorbax 
SB-CN column (i.d. $4.6 \times 150 \mathrm{~mm}$ ). The mobile phase consisted of $450 \mathrm{~mL} 50 \mathrm{mM}$ sodium dihydrogen phosphate, $300 \mathrm{~mL}$ acetonitrile and $50 \mathrm{~mL}$ methanol, adjusted to pH 7.3 with $10 \mathrm{~N}$ sodium hydroxide. Using a flow rate of $1 \mathrm{~mL} / \mathrm{min}$, the retention times of the compounds to be analysed were $7.7 \mathrm{~min}$ (14-hydroxy-clarithromycin), $13.1 \mathrm{~min}$ (clarithromycin) and $14.7 \mathrm{~min}$ (roxithromycin, internal standard).

\section{Serum}

To $500 \mu \mathrm{L}$ serum were added: $100 \mu \mathrm{L}$ water (standards: $100 \mu \mathrm{L}$ water containing $1 \mu \mathrm{g}$ clarithromycin and $0.5 \mu \mathrm{g}$ 14-hydroxy-clarithromycin), $100 \mu \mathrm{L}$ internal standard solution $(10 \mu \mathrm{g} / \mathrm{mL}$ roxithromycin in water) and $500 \mu \mathrm{L}$ acetonitrile for precipitation of proteins. Mixing was followed by incubation at $4^{\circ} \mathrm{C}$ for $20 \mathrm{~min}$ and centrifugation. The supernatant was diluted with $1 \mathrm{~mL}$ water and transferred into a disposable column (ADSORBEX $^{\mathrm{R}}$ filled with $100 \mathrm{mg} \mathrm{C18}$ silicagel, Merck Company; Darmstadt, Germany) which had been equilibrated with $5 \mathrm{~mL}$ of methanol followed by $2 \mathrm{~mL}$ of $50 \mathrm{~mm}$ sodium phosphate buffer $(\mathrm{pH}=6.3)$. After the supernatant had passed through the extraction column, it was washed twice with $2.5 \mathrm{~mL}$ of $50 \mathrm{~mm}$ phosphate buffer ( $\mathrm{pH}=6 \cdot 3$ ). The compounds to be investigated were eluted with $1 \mathrm{~mL}$ methanol which was subsequently diluted with $1 \mathrm{~mL}$ water and then $50 \mu \mathrm{L}$ was injected into the analytical column.

\section{Sputum}

An aliquot of the sputum was adsorbed on to a dental tampon and then transferred to a SALIVETTE ${ }^{R}$ (Sarstedt Company, Nuembrecht, Germany) and centrifuged (1500 g, $20 \mathrm{~min}$ ). Up to $500 \mu \mathrm{L}$ of the sol phase fluid was treated in the same manner as serum. The methanol eluate from the extraction column was dried under vacuum in a EVAPOTEC $^{R}$ Vortex-Evaporator (Haake Buchler Company, Saddle Brook, NJ, USA). The residue was reconstituted in $300 \mu \mathrm{L}$ of mobile phase and vortex-mixed for $5 \mathrm{sec}$. An aliquot of $10-20 \mu \mathrm{L}$ was injected into the analytical column.

\section{Calculation of pharmacokinetic parameters}

For each patient, $C_{\max }$ was determined as the highest concentration of clarithromycin or 14-hydroxy-clarithromycin achieved in serum or sputum for each dosage of clarithromycin. A mean $C_{\max }$ was calculated for clarithromycin or 14-hydroxy-clarithromycin as the mean of the individual $C_{\max }$ values obtained from each of the eight patients. Similarly mean $T_{\max }$ was determined for clarithromycin and 14-hydroxy-clarithromycin in sputum and serum for each dosage of clarithromycin. The sputum to serum ratio for clarithromycin and 14-hydroxy-clarithromycin was determined for each individual time point as the percentage ratio of sputum concentration of clarithromycin or 14-hydroxyclarithromycin to that of a simultaneous serum sample. The elimination constants $\left(k_{\mathrm{et}}\right)$ for clarithromycin and 14-hydroxy-clarithromycin in serum were calculated from the terminal part of the $\log _{c}$ serum concentration versus time curve. The half-lives of clarithromycin and 14 hydroxy-clarithromycin were calculated by using the formula $T_{1 / 2}=-0.6931 / k_{\mathrm{ed}}($ Clark \& Smith, 1986). 
Table I. Serum concentrations of clarithromycin and 14-hydroxyclarithromycin after a single oral dose of $250 \mathrm{mg}$ and $500 \mathrm{mg}$ clarithromycin

\begin{tabular}{lcccc}
\hline \multirow{2}{*}{$\begin{array}{l}\text { Dose } \\
\text { time (h) }\end{array}$} & \multicolumn{2}{c}{$250 \mathrm{mg} \mathrm{CL}$} & \multicolumn{2}{c}{$500 \mathrm{mg} \mathrm{CL}$} \\
& $\mathrm{CL}(\mathrm{mg} / \mathrm{L})$ & $\mathrm{HCL}(\mathrm{mg} / \mathrm{L})$ & $\mathrm{CL}(\mathrm{mg} / \mathrm{L})$ & $\mathrm{HCL}(\mathrm{mg} / \mathrm{L})$ \\
\hline 0 & $0 \pm 0$ & $0 \pm 0$ & $0 \pm 0$ & $0 \pm 0$ \\
1 & $0.76 \pm 0.64$ & $0.20 \pm 0.18$ & $2 \cdot 11 \pm 1.75$ & $0.55 \pm 0.46$ \\
2 & $0.93 \pm 0.59$ & $0.31 \pm 0.16$ & $2.65 \pm 1.43$ & $0.56 \pm 0.38$ \\
4 & $0.75 \pm 0.42$ & $0.28 \pm 0.10$ & $2.12 \pm 1.02$ & $0.57 \pm 0.36$ \\
8 & $0.54 \pm 0.34$ & $0.23 \pm 0.08$ & $1.31 \pm 0.57$ & $0.45 \pm 0.24$ \\
24 & $0.09 \pm 0.09$ & $0.07 \pm 0.06$ & $0.28 \pm 0.24$ & $0.14 \pm 0.10$ \\
\hline
\end{tabular}

All data are means of eight patients \pm standard deviation. CL, Clarithromycin; HCL, 14-hydroxy-clarithromycin.

\section{Calibration and control samples}

Internal standardization using roxithromycin and quality control was performed by assaying spiked samples with each run. The detection limit was $400 \mathrm{pg}$ for clarithromycin and 14-hydroxy-clarithromycin and $600 \mathrm{pg}$ for roxithromycin.

\section{Statistical analysis}

A repeated measure analysis of variance was undertaken to determine differences in the mean concentration between drug doses and whether there was a change in concentration with time. The $C_{\max }$ of sputum and serum were compared by Wilcoxon signed rank test. A $P$ value of less than 0.05 was taken as significant. All analyses were performed with the aid of the statistical package BMDP (BMDP, 1990).

\section{Results}

\section{Serum concentrations (Table I)}

The mean concentrations of clarithromycin and 14-hydroxy-clarithromycin were significantly higher in the $500 \mathrm{mg}$ group than in the $250 \mathrm{mg}$ group $(P<0.05)$. The concentrations of clarithromycin and 14-hydroxy-clarithromycin increased until $C_{\max }$ was reached, thereafter decreasing with time. As there were relatively few time points for sampling, half-lives calculated are very variable and there is no evidence of any difference in the half-lives calculated for both doses (Table III). The $C_{\max }$ for clarithromycin (250 mg) and 14-hydroxy-clarithromycin were $1.20 \pm 0.39 \mathrm{mg} / \mathrm{L}$ and $0.37 \pm 0.10 \mathrm{mg} / \mathrm{L}$ respectively, which occurred at 3 and $3.1 \mathrm{~h}$. The $C_{\max }$ of clarithromycin $(500 \mathrm{mg})$ and 14-hydroxy-clarithromycin were $2.78 \pm 1.31 \mathrm{mg} / \mathrm{L}$ and $0.68 \pm 0.36 \mathrm{mg} / \mathrm{L}$ respectively, which occurred at 2.5 and $2.6 \mathrm{~h}$, and were significantly higher than those following clarithromycin $(250 \mathrm{mg})(P<0.05)$.

\section{Sputum concentrations (Table II)}

The mean concentrations of clarithromycin $(P<0-01)$ and 14-hydroxy-clarithromycin $(P<0.05)$ were significantly higher in the $500 \mathrm{mg}$ group than in the $250 \mathrm{mg}$ group. The concentrations of clarithromycin and 14-hydroxy-clarithromycin increased until $C_{\max }$, thereafter decreasing with time. Sputum half-lives were not calculated in view of the 
Table II. Sputum concentrations of clarithromycin and 14-hydroxyclarithromycin in patients following a single oral dose of $250 \mathrm{mg}$ and $500 \mathrm{mg}$ clarithromycin

\begin{tabular}{lcccc}
\hline Dose & \multicolumn{2}{c}{$250 \mathrm{mg} \mathrm{CL}$} & \multicolumn{2}{c}{$500 \mathrm{mg} \mathrm{CL}$} \\
time (h) & $\mathrm{CL}(\mathrm{mg} / \mathrm{L})$ & $\mathrm{HCL}(\mathrm{mg} / \mathrm{L})$ & $\mathrm{CL}(\mathrm{mg} / \mathrm{L})$ & $\mathrm{HCL}(\mathrm{mg} / \mathrm{L})$ \\
\hline 0 & $0 \pm 0$ & $0 \pm 0$ & $0 \pm 0$ & $0 \pm 0$ \\
4 & $0.43 \pm 0.34$ & $0.24 \pm 0.26$ & $1.49 \pm 1.02$ & $0.43 \pm 0-25$ \\
8 & $0.44 \pm 0.23$ & $0.26 \pm 0.16$ & $0.91 \pm 0.39$ & $0.33 \pm 0.13$ \\
24 & $0.10 \pm 0.07$ & $0-05 \pm 0.05$ & $0.37 \pm 0-29$ & $0.17 \pm 0.16$ \\
\hline
\end{tabular}

All data are means of eight patients \pm standard deviation. CL, Clarithromycin; HCL, 14-hydroxy-clarithromycin.

limited data. The $C_{\max }$ of clarithromycin $(250 \mathrm{mg})$ and 14-hydroxy-clarithromycin in sputum were $0.52 \pm 0.30$ and $0.30 \pm 0.24 \mathrm{mg} / \mathrm{L}$ respectively which occurred at $5 \mathrm{~h}$ and $6.5 \mathrm{~h}$ (Table III). The $C_{\max }$ of clarithromycin $(500 \mathrm{mg})$ and 14-hydroxy-clarithromycin were $1.59 \pm 1.00 \mathrm{mg} / \mathrm{L}$ and $0.47 \pm 0.23 \mathrm{mg} / \mathrm{L}$ respectively which occurred at 5 and $5.5 \mathrm{~h}$. At $C_{\max }$, only sputum clarithromycin concentration was significantly higher following $500 \mathrm{mg}$ clarithromycin compared with $250 \mathrm{mg}$ clarithromycin $(P<0.05)$. The sputum/ serum percentage ratios at $C_{\max }$ (sputum) for clarithromycin and 14-hydroxy-clarithromycin were $74.3 \%$ and $113.9 \%$ (250 mg clarithromycin) and $94.7 \%$ and $99.9 \%$ (500 mg clarithromycin) respectively.

\section{Discussion}

These results confirm previously published reports that orally administered clarithromycin is rapidly absorbed and elimination from serum is slow (Ferrero, 1990; Davey, 1991). Peak serum concentrations were achieved $3 \mathrm{~h}$ after oral administration of 250 and $500 \mathrm{mg}$ of clarithromycin, while peak sputum concentrations were achieved after $5 \mathrm{~h}$. In this study, the mean serum concentrations of clarithromycin and 14-hydroxyclarithromycin are comparable to results of studies performed on healthy individuals (Ferrero, 1990; Davey, 1991).

Measurement of antibiotic penetration into the lung is difficult because of the heterogeneity of tissue demonstrated in studies of bronchial biopsies (Baldwin et al., 1992) and lung parenchyma tissue obtained at thoracotomy, which are often contaminated with blood (Valcke et al., 1990). Antibiotic concentrations in epithelial lining fluid can be obtained by bronchoalveolar lavage (Baldwin et al., 1991) and contamination minimized by microlavage, but may not be representative of those in bronchial mucus. Similarly, bronchial mucus can only be obtained at bronchoscopy, which must be repeated for pharmacokinetic studies. The use of sputum is convenient but is also complicated by contamination with saliva, stagnant mucus (i.e. present before antibiotic was taken) and $\beta$-lactamase; furthermore, it may be difficult to obtain adequate fresh specimens (Pennington, 1981). In this study, the choice of stable bronchiectasis patients who regularly produced mucoid sputum, and expectoration assisted by physiotherapists may have overcome many of these problems.

The concentration of antibiotic at the site of infection may be more important than serum concentrations in patients with bronchial infections. Recent in-vivo and in-vitro studies have shown that bacteria are associated with damaged epithelium, and parti- 
Table III. Pharmacokinetic data for clarithromycin (CL) and 14-hydroxy-clarithromycin (HCL) following a single oral dose.

\begin{tabular}{|c|c|c|c|c|c|c|c|c|}
\hline & \multicolumn{4}{|c|}{$250 \mathrm{mg} \mathrm{CL}$} & \multicolumn{4}{|c|}{$500 \mathrm{mg} \mathrm{CL}$} \\
\hline & serum CL & sputum CL & serum HCL & sputum HCL & serum CL & sputum CL & serum HCL & sputum HCL \\
\hline$C_{\max }(\mathrm{mg} / \mathrm{L})$ & $\begin{array}{l}1 \cdot 2 \pm 0.39 \\
(0-7-1 \cdot 89)\end{array}$ & $\begin{array}{l}0.52 \pm 0.3 \\
(0.23-1 \cdot 14)\end{array}$ & $\begin{array}{l}0.37 \pm 0.1 \\
(0.25-0.5)\end{array}$ & $\begin{array}{r}0.3 \pm 0.24 \\
(0.15-0.86)\end{array}$ & $\begin{array}{c}2.78 \pm 1.31 \\
(1.07 \pm 5.59)\end{array}$ & $\begin{array}{l}1.59 \pm 1 \cdot 0 \\
(0.62-3.49)\end{array}$ & $\begin{array}{l}0.68 \pm 0.36 \\
(0.19-1.44)\end{array}$ & $\begin{array}{l}0.47 \pm 0.23 \\
(0.12-0.85)\end{array}$ \\
\hline$T_{\max }(\mathrm{h})$ & $\begin{array}{c}3 \cdot 0 \pm 2 \cdot 3 \\
(1-8)\end{array}$ & $\begin{array}{c}5 \cdot 0 \pm 1 \cdot 9 \\
(4-8)\end{array}$ & $\begin{array}{c}3 \cdot 1 \pm 2 \cdot 2 \\
(1-8)\end{array}$ & $\begin{array}{c}6 \cdot 5 \pm 2 \cdot 1 \\
(4-8)\end{array}$ & $\begin{array}{c}2 \cdot 5 \pm 2 \cdot 3 \\
(1-8)\end{array}$ & $\begin{array}{c}5 \cdot 0 \pm 1 \cdot 9 \\
(4-8)\end{array}$ & $\begin{array}{c}2 \cdot 6 \pm 2 \cdot 6 \\
(1-8)\end{array}$ & $\begin{array}{c}5 \cdot 5 \pm 2 \cdot 1 \\
(4-8)\end{array}$ \\
\hline$T_{1 / 2}(\mathrm{~h})$ & $\begin{array}{l}8 \cdot 0 \pm 4 \cdot 9 \\
(3 \cdot 4-18 \cdot 2)\end{array}$ & - & $\begin{array}{c}10 \cdot 1 \pm 4 \cdot 5 \\
(3 \cdot 6-16 \cdot 4)\end{array}$ & - & $\begin{array}{c}6 \cdot 9 \pm 3 \cdot 0 \\
(4 \cdot 3 \pm 11 \cdot 6)\end{array}$ & - & $\begin{array}{l}12 \cdot 4 \pm 15 \cdot 0 \\
(3 \cdot 6 \pm 46 \cdot 1)\end{array}$ & - \\
\hline
\end{tabular}

Data are means \pm S.D. and range obtained from eight patients. 
cularly with intraluminal secretions in the lower respiratory tract (Farley et al., 1986; Baltimore et al., 1989; Read et al., 1991). Therefore penetration into these sites may influence the efficacy of an antibiotic. Many antibiotics, particularly the penicillins, have poor penetration into bronchial secretions (Bergogne-Berezin, 1988; Valcke et al., 1990). In the present study, the the penetration of clarithromycin and 14-hydroxyclarithromycin into sputum was rapid and the concentrations achieved were higher than those previously reported for $\beta$-lactam antibiotics. Drug elimination of clarithromycin and 14-hydroxy-clarithromycin from sputum was slow and measurable concentrations of antibiotics were still present in sputum $24 \mathrm{~h}$ after a single oral dose of clarithromycin. For both doses of clarithromycin administered, the sputum to serum ratio of clarithromycin ranged from $31.9 \%$ to $257.8 \%$ and 14-hydroxy-clarithromycin ranged from $40.4 \%$ to $277.9 \%$. Clarithromycin has also been shown to have good penetration into lung tissue ( $C_{\max }$ lung tissue $17.47 \mathrm{mg} / \mathrm{kg}$ and $C_{\max }$ serum $2.82 \mathrm{mg} / \mathrm{L}$ ) following multiple doses of $500 \mathrm{mg}$ taken orally (Fraschini et al., 1991). Previous studies on erythromycin generally used multiple doses of erythromycin and have shown that the penetration of erythromycin ranges from $10 \%$ to $50 \%$ for bronchial secretions and sputum (Marlin et al., 1980; Bergogne-Berezin, 1988; Periti et al., 1989), 83\% for bronchial mucus (Brun $e t$ al., 1981), and $110 \%$ to $320 \%$ for lung parenchyma (Wollmer et al., 1982). Our results indicate that clarithromycin has a higher penetration into respiratory mucus than erythromycin. Further studies are needed to determine whether clarithromycin and 14-hydroxy-clarithromycin accumulate in sputum after multiple doses.

The mean sputum concentrations of clarithromycin and 14-hydroxy-clarithromycin were compared with the MICs for common respiratory pathogens (King \& Phillips, 1991; Piscitelli, Danziger \& Rodvold, 1992). After administration of the two doses of clarithromycin, sputum concentrations of clarithromycin and 14-hydroxy-clarithromycin exceeded the MICs for Streptococcus pneumoniae $(0.12 \mathrm{mg} / \mathrm{L}$ for clarithromycin $0-015 \mathrm{mg} / \mathrm{L}$ for 14-hydroxy-clarithromycin), Moraxella catarrhalis $(0.12 \mathrm{mg} / \mathrm{L}$, $0.12 \mathrm{mg} / \mathrm{L})$, and Streptococcus pyogenes $(0.06 \mathrm{mg} / \mathrm{L}, 0.03 \mathrm{mg} / \mathrm{L})$, for more than $24 \mathrm{~h}$, except following $250 \mathrm{mg}$ doses, when the MIC for Streptococcus pneumoniae (clarithromycin) was exceeded for $21.5 \mathrm{~h}$ and Moraxella catarrhalis when the MIC was exceeded for $21.5 \mathrm{~h}$ (clarithromycin) and $16.5 \mathrm{~h}$ (14-hydroxy-clarithromycin). MICs for Haemophilus influenzae vary considerably: $2-16 \mathrm{mg} / \mathrm{L}$ in one study, $0.75-4 \mathrm{mg} / \mathrm{L}$ in another (Dabernat et al., 1991; Olsson-Liljequist \& Hoffman, 1991). However, the MIC for $H$. influenzae was not exceeded in sputum following either single dose of clarithromycin. Multiple doses of clarithromycin are known to increase the serum concentrations of clarithromycin, which may be reflected in sputum concentrations. Although sputum concentrations of clarithromycin and 14-hydroxy-clarithromycin are below the MIC for $H$. influenzae, clarithromycin has been shown to be effective in treatment of patients with infective exacerbation of chronic bronchitis caused by $H$. influenzae (Guay \& Craft, 1992). The recent finding that $H$. influenzae infection caused less tissue damage in the presence of subinhibitory antibiotic concentrations may be relevant in these circumstances (Tsang et al., 1993).

Macrolide antibiotics have been used more frequently of late because of recognition of infections caused by bacteria not sensitive to $\beta$-lactams, such as mycoplasma, legionella and chlamydia. Clarithromycin has good sputum penetration in patients with clinically stable bronchiectasis. This property, and its superior pharmacokinetic profile, give it clear advantages over older macrolide antibiotics such as erythromycin. 


\section{Acknowledgements}

The authors would like to thank Miss Jane Burditt for secretarial assistance, Mr D. Lowson for statistical advice, the nurses and physiotherapists of the Lind Gallery of the Royal Brompton National Heart and Lung Hospital for their invaluable help and Abbott Laboratories for supporting the study.

Presented in part at the Summer Meeting 1992, British Pharmacology Society and abstract published in British Journal of Clinical Pharmacology (1993; 35: 84).

\section{References}

Baldwin, D. R., Wise, R., Andrews, J. M. \& Honeybourne, D. (1991). Microlavage-a technique for detecting the volume of epithelial lining fluid. Thorax 46, 658-62.

Baldwin, D. R., Wise, R., Andrews, J. M. \& Honeybourne, D. (1992). Quantitative morphology and water distribution of bronchial biopsy specimens. Thorax 47, 504-7.

Baltimore, R. S., Christie, C. D. C. \& Walker-Smith, G. J. (1989). Immunohistopathologic localisation of Pseudomonas aeruginosa in lungs from patients with cystic fibrosis. American Review of Respiratory Diseases 140, 1650-61.

Bergogne-Berezin, E. (1988). Pharmacokinetics of antibiotics in respiratory secretions. In Respiratory Infections: Diagnosis and Management (Pennington, J. E., Ed.), 2nd edn, pp. 608-31. Raven Press, New York.

BMDP (1990). Statistical Software. University of California Press, CA.

Brun, Y., Forney, F., Gamondes, J. P., Tebib, A., Brune, J. \& Fleurette, J. (1981). Levels of erythromycin in pulmonary tissue and bronchial mucus compared to those of amoxycillin. Journal of Antimicrobial Chemotherapy 8, 459-66.

Clark, B. \& Smith, D. A. (1986). An Introduction to Pharmacokinetics, 2nd edn. Blackwell Scientific Publications.

Dabernat, H., Delmas, C., Seguy, M., Fourtillan, J. B., Girault, J. \& Lareng, M. B. (1991). The activity of clarithromycin and its 14hydroxy metabolite against Haemophilus influenzae, determined by in vitro and serum bactericidal tests. Journal of Antimicrobial Chemotherapy 27, Suppl. A, 19-30.

Davey, P. G. (1991). The pharmacokinetics of clarithromycin and its 14-OH metabolite. Journal of Hospital Infection 19, Suppl. A, 29-37.

Farley, M. W., Stephens, D. S., Mulks, M. H., Cooper, M. D., Bricker, J. V., Mirra, S. S. et al. (1986). Pathogenesis of IgA protease-producing and non-producing Haemophilus influenzae in human nasopharyngeal organ cultures. Journal of Infectious Diseases 154, 752-9.

Ferrero, J. L., Bopp, B. A., Marsh, K. C., Quigley, S. C., Johnson, N. J., Anderson, D. J. et al. (1990). Metabolism and disposition of clarithromycin in man. Drug Metabolism and Disposition: The Fate of Chemicals 18, 441-6.

Fraschini, F., Scaglione, F., Pintucci, G., Maccarinelli, G., Dugnani, S. \& Demartini, G. (1991). The diffusion of clarithromycin and roxithromycin into nasal mucosa, tonsil and lung in humans. Journal of Antimicrobial Chemotherapy 27, Suppl. A, 61-5.

Guay, D. R. P. \& Craft, J. C. (1992). Comparative safety and efficacy of clarithromycin and ampicillin in the treatment of out-patients with acute bacterial exacerbation of chronic bronchitis. Journal of Internal Medicine 231, 295-301.

Hardy, D. J., Swanson, R. A., Rode, R. N., Marsh, K., Shipkowitz, N. L. \& Clement, J. J. (1990). Enhancement of the in vitro and in vivo activities of clarithromycin against Haemophilus influenzae by 14-hydroxy-clarithromycin, its major metabolite in humans. Antimicrobial Agents and Chemotherapy 34, 1407-13.

King, A. \& Phillips, I. (1991). A comparison of the in-vitro activity of clarithromycin, a new macrolide antibiotic, with erythromycin and other oral agents. Journal of Hospital Infection 19. Suppl. A, 3-9.

Marlin, G. E., Davis, P. R., Rutland, J. \& Berend, N. (1980). Plasma and sputum erythromycin concentrations in chronic bronchitis. Thorax 35, 441-5.

Olsson-Liljequist, B. \& Hoffman, B. M. (1991). In vitro activity of clarithromycin combined with its 14-hydroxy metabolite A-62671 against Haemophilus influenzae. Journal of Antimicrobial Chemotherapy 27, Suppl. A, 11-7. 
Pennington, J. E. (1981). Penetration of antibiotics into respiratory secretions. Review of Infectious Diseases 3, 67-73.

Periti, P., Mazzei, T., Mini, E. \& Novelli, A. (1989). Clinical pharmacokinetic properties of the macrolide antibiotics. Clinical Pharmacokinetics 16, 193-214.

Piscitelli, S. C., Danziger, L. H. \& Rodvold, K. A. (1992). Clarithromycin and azithromycin: new macrolide antibiotics. Clinical Pharmacokinetics 11, 137-52.

Read, R. C., Wilson, R., Rutman, A., Lund, V., Todd, H. C., Brain, A. P. R. et al. (1991). Interaction of non-typable Haemophilus influenzae with human respiratory mucosa in vitro. Journal of Infectious Diseases 163, 549-58.

Tsang, K. W. T., Rutman, A., Kanthakumar, K., Belcher, J., Lund, V., Roberts, D. et al. (1993). Haemophilus influenzae infection of human respiratory mucosa in low concentrations of antibiotics. American Review of Respiratory Diseases 148, 201-7.

Valcke, Y., Pauwels, R. \& Van der Straeten, M. (1990). Pharmacokinetics of antibiotics in the lungs. European Respiratory Journal 3, 715-22.

Wollmer, P., Rhodes, C. G., Pike, V. W., Silvester, D. J., Pride, N. B., Sanders, A. et al. (1982). Measurement of pulmonary erythromycin concentration in patients with lobar pneumonia by means of positron tomography. Lancet ii, 1361-4.

(Received 4 March 1993; revised version accepted I November 1993) 